Article

\title{
Thermodynamic Selection of the Optimal Working Fluid for Organic Rankine Cycles
}

\author{
Attila R. Imre ${ }^{1,2}{ }^{2}$, Réka Kustán ${ }^{1}$ and Axel Groniewsky ${ }^{1}$ \\ 1 Department of Energy Engineering, Budapest University of Technology and Economics, Muegyetem rkp. 3, \\ H-1111 Budapest, Hungary; kustan@energia.bme.hu (R.K.); groniewsky@energia.bme.hu (A.G.) \\ 2 Centre for Energy Research, Department of Thermohydraulics, Hungarian Academy of Science, P.O. Box 49, \\ H-1525 Budapest, Hungary \\ * Correspondence: imreattila@energia.bme.hu or imre.attila@energia.mta.hu
}

Received: 6 May 2019; Accepted: 24 May 2019; Published: 27 May 2019

check for updates

\begin{abstract}
A novel method proposed to choose the optimal working fluid-solely from the point of view of expansion route-for a given heat source and heat sink (characterized by a maximum and minimum temperature). The basis of this method is the novel classification of working fluids using the sequences of their characteristic points on temperature-entropy space. The most suitable existing working fluid can be selected, where an ideal adiabatic (isentropic) expansion step between a given upper and lower temperature is possible in a way, that the initial and final states are both saturated vapour states and the ideal (isentropic) expansion line runs in the superheated (dry) vapour region all along the expansion. Problems related to the presence of droplets or superheated dry steam in the final expansion state can be avoided or minimized by using the working fluid chosen with this method. Results obtained with real materials are compared with those gained with model (van der Waals) fluids; based on the results obtained with model fluids, erroneous experimental data-sets can be pinpointed. Since most of the known working fluids have optimal expansion routes at low temperatures, presently the method is most suitable to choose working fluids for cryogenic cycles, applied for example for heat recovery during LNG-regasification. Some of the materials, however, can be applied in ranges located at relatively higher temperatures, therefore the method can also be applied in some limited manner for the utilization of other low temperature heat sources (like geothermal or waste heat) as well.
\end{abstract}

Keywords: adiabatic expansion; isentropic expansion; T-s diagram; working fluid classification; optimization

\section{Introduction}

For converting the heat of low-temperature heat sources into electricity, the Organic Rankine Cycle (ORC) is often applied [1,2]. There are several known-and probably even more unknown-low boiling-point working fluids that can be used to convert heat into work. The selection of the ideal working fluid for a given heat reservoir requires a multi-dimensional optimization method; selection criteria include thermodynamic and physical properties, chemical stability, chemical compatibility, environmental impacts, safety, production costs, availability of the fluid and several other parameters [1,3,4]. Some of these parameters are more important than the others and even the rank of importance can be different in various locations or time, making the evaluation process even more difficult. Based on the evaluation of those criteria, one might obtain various indicators for each of these criteria, reflecting the performance of a given working fluid and the corresponding layout. Then these indicators can be combined [5]-with proper weight-to a comprehensive evaluation indicator to rank the working fluids and to find the best of them [6]. For this kind of evaluation, all sub-evaluation steps focusing only on a single aspect should be as accurate as possible. 
For this reason, we are focusing on one segment of this optimization method, related to the selection of the proper working fluid to avoid wet or superheated vapour states at the end of the expansion process; in this case, one might use the simplest ORC layout, using only four units, including a pump, a heat exchanger, an expander and a second heat exchanger. Starting the expansion from a saturated vapour state and using wet working fluid, the expansion is terminated in a mixed-phase state, in the so-called wet vapour region. Here, the vapour contains dispersed liquid (droplets), which can cause loss of efficiency as well as damage of expander due to droplet erosion. To avoid erosion problems, one can use a droplet separator device to remove the liquid part. Also, it is possible to apply superheating (i.e., increase of the fluid temperature from the saturated vapour state to a superheated dry vapour state); in this case, an additional heat exchanger section (superheater) is needed. Using dry fluid and starting the expansion from a saturated vapour state, the expansion has to be terminated in a low-temperature superheated dry vapour state. Here, some residual heat has to be removed from the working fluid before condensation. This can cause some problems, including loss of efficiency or high cooling load of the condenser. To avoid these problems, one might choose the inclusion of an extra heat exchanger, called recuperator, which cools the superheated vapour before reaching the condenser and preheats the liquid (i.e., recovers some of the lost heat) before reaching the evaporator. The best solution would be the application of an isentropic working fluid, where ideal adiabatic expansions could run along (or nearby) the saturated vapour states during the whole expansion process. In this case a simple set-up of two heat exchangers, a pump and an expander could be sufficient to convert the heat to work by ORC. Unfortunately, such an ideal isentropic fluid does not exist; all real fluids classified as isentropic one have a reverse S-shaped saturated vapour branch on T-s diagram, not a straight line with infinite slope, assumed by isentropicity. This is also true for fluids described by various molecular or equation of state based models [7-13].

Using our method, for a given heat source-heat sink pair one can select a real, one-component working fluid from a database [14], with an ideal adiabatic (isentropic) expansion process starting from a saturated vapour state and terminating also in a saturated vapour state (or at least in the vicinity of this state), utilizing the "belly" of the reverse S-shaped saturated vapour branches of various materials. In this way, one can use the simplest ORC layout, consisting of only a pump, two heat exchangers (evaporator, condenser) and an expander, avoiding the use of superheater or droplet separator and a recuperative heat exchanger (recuperator). Since the fluid is always in dry condition during expansion, droplet erosion of the expander can also be avoided. Concerning the description of different set-ups used with various working fluids, more details can be seen for example in $[1,8]$.

Presently, we have a database of around 30 pure fluids with T-s data taken from the NIST Chemistry WebBook [15] and from RefProp 9.1 [16]. Only fluids with properly accurate T-s data are included into the database; they are the ones where $T$-s data are calculated by high-accuracy reference equations, instead of any other general equations of states. Most of these fluids were termed formerly as dry and a very few of them as isentropic, while in the novel classification they are in various isentropic sub-classes, namely in ANCMZ, ACNMZ, ANZCM and ANCZM.

From the present working fluid set, one can choose the thermodynamically most suitable material for a given ORC-cycle. Due to the temperature range covered by the $T$-s data, these fluids should be proper candidates mostly for cryogenic cycles, but after proper expansion, the database can be used for other temperature ranges (like geothermal, solar or waste heat applications) as well.

\section{Maps of Potential Expansion Routes}

According to the novel classification scheme, working fluids are classified by the entropy-sequences of their so-called primary and secondary characteristic points on the T-s diagram:

- Points $\mathrm{A}$ and $\mathrm{Z}$ are the initial and final points of the T-s saturation curve. Physically it is related to the triple point (or freezing point)

- Point $C$ is the critical point, located on the top of the curve, separating the liquid branch (A-C) and the vapour branch $(\mathrm{C}-\mathrm{Z})$

- Points $\mathrm{M}$ and $\mathrm{N}$ are local or global entropy extrema, located on the vapour branch. 
Points A, Z and C exist for all working fluids (these are the primary points), while M exists only for dry and isentropic ones and $\mathrm{N}$ exists only for isentropic ones (therefore these are the secondary points). Theoretically, eight different classes can exist, one of them is wet (ACZ), two of them are dry (ACZM and AZCM) and five of them are "real" isentropics, with reverse S-shaped vapour branch (ANZCM, ANCZM, ANCMZ, ACNMZ and ACNZM). Concerning real materials, examples can be found only for six of these classes, neither ACZM, nor ACNZM have been found up to now. Some of these real isentropic fluids (characterized by five-letter sequences) were considered formerly as dry ones, being the point $\mathrm{N}$ well below ambient temperatures. Using this classification, one can easily correlate simple material properties like molar volume [12] or molar isochoric heat capacity [14] with the classification, i.e., separate wet and dry working fluids. Also, it can be used easily to study the behaviour of working fluids during the expansion process of ORC and other similar cycles [17].

The above mentioned reverse S-shape allows us to define isentropic expansion routes. Two different T-s diagrams are shown in Figure 1, for 2-methylbutane (a) and benzene (b). It can be seen, that although none of them is an isentropic working fluid according to the traditional wet-dry-isentropic classification, one can still define isentropic expansion routes starting and terminating on the saturated vapour branch; these routes are marked as $1 \rightarrow 2$ and $3 \rightarrow 4$. For both materials, all potential isentropic expansion routes located in a "bay", separated by a limiting expansion line (grey dashed one) from the rest of the diagram. For ANCMZ-type working fluids, the limiting line is defined by the $M \rightarrow M_{s}^{d}$ expansion route; this is also true for ACNMZ-types. For ANCZM types, the limiting line is defined by the $Z_{\mathrm{s}}^{\mathrm{u}} \rightarrow \mathrm{Z}$ expansion route; the same is true for ANZCM types.
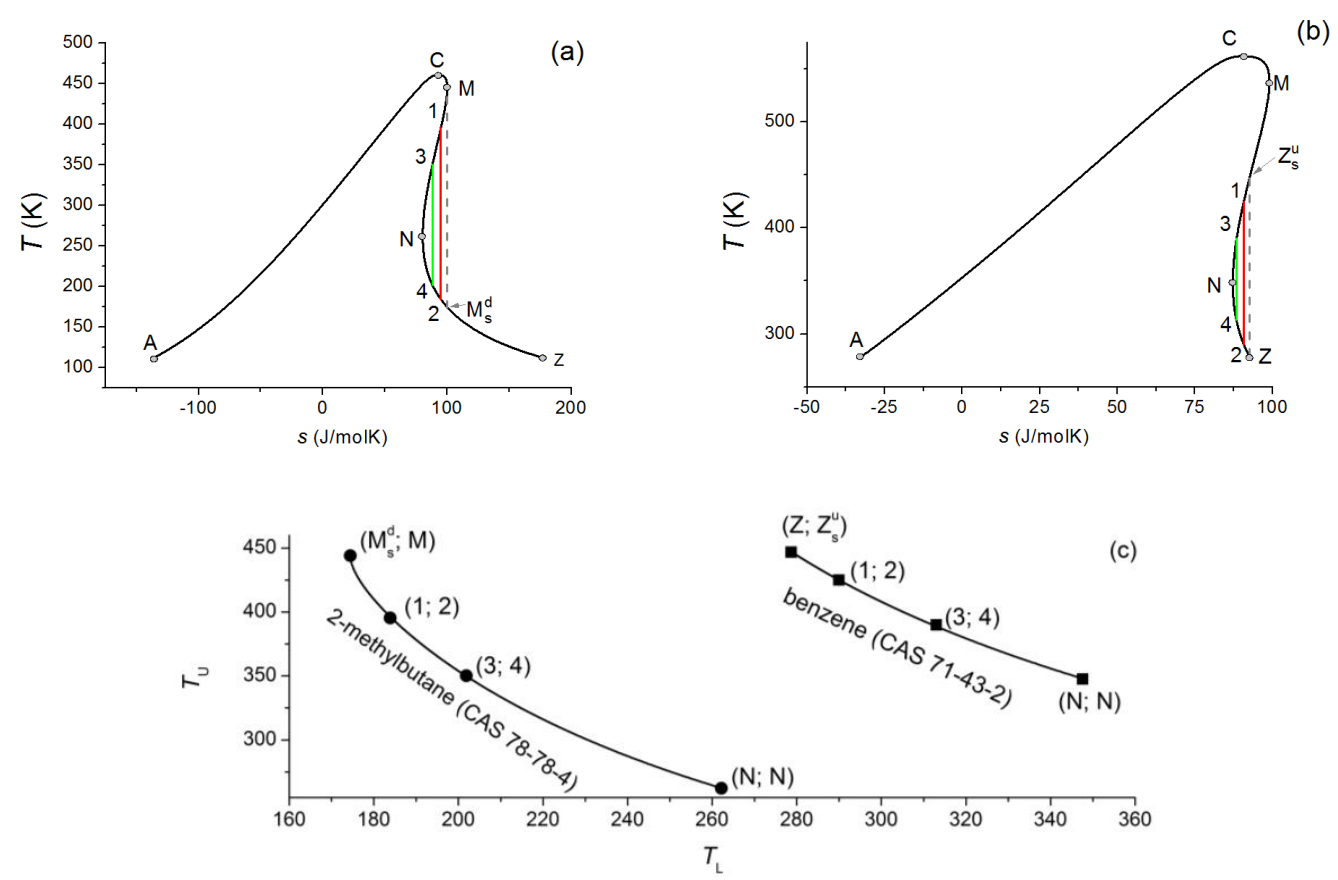

Figure 1. Potential isentropic expansion routes $(1 \rightarrow 2$ and $3 \rightarrow 4)$ for working fluids classified as ANCMZ (a; 2-methylbutane) and as ANCZM (b; benzene). Limiting expansion curves marked by dashed grey lines from $\mathrm{M} \rightarrow \mathrm{M}_{\mathrm{s}}^{\mathrm{d}}(\mathbf{a})$ and $\mathrm{Z}_{\mathrm{s}}^{\mathrm{u}} \rightarrow \mathrm{Z}(\mathbf{b})$. Figure (c) shows the way of constructing a $T_{\mathrm{L}}-T_{\mathrm{U}}$ diagram representing expansion routes for each material. One material is represented by one curve and one point of the given curve illustrates one expansion process with a given upper (starting) and lower (finishing) temperature. Numbers and letters on $(\mathbf{a}, \mathbf{c})$ and $(\mathbf{b}, \mathbf{c})$ figures are corresponding ones.

Here, $\mathrm{Z}_{\mathrm{s}}^{\mathrm{u}}$ and $\mathrm{M}_{\mathrm{s}}^{\mathrm{d}}$ are the so-called tertiary characteristic points, marking the intersection on the saturation curve projecting the primary and secondary ones. Subscript s refers to the route of the projection (to the s-axis), while superscript $u$ and $d$ refers to the relative location compared to the original point (u: up; d: down). 
Each expansion process can be represented by an upper and a lower temperatures $\left(T_{\mathrm{U}}\right.$ and $\left.T_{\mathrm{L}}\right)$, where expansion starts and stops. In this way, one can construct a $T_{\mathrm{L}}-T_{\mathrm{U}}$ diagram (shown in Figure 1c) illustrating expansion routes for each material. One material is represented by one curve and one point of the given curve represents one expansion process with a given upper (starting) and lower (finishing) temperature. Numbers and letters on a-c (2-methylbutane) and b-c (benzene) figures are corresponding ones.

Concerning the $T-s$ diagrams used here, the specific entropy values are given for moles, instead of mass (i.e., in $\mathrm{J} / \mathrm{molK}$, instead of $\mathrm{J} / \mathrm{kgK}$ ). Although it is not usual in engineering applications, it has been shown recently, that for the comparison of various working fluids, the mole-based quantities are more suitable than the mass-based ones [14].

Using 28 materials with reverse S-shaped vapour branch and with T-s diagrams available in the NIST databases (NIST Chemistry WebBook [15] and from RefProp 9.1 [16]), one can construct a map for all potential routes; this map is shown in Figure 2. The lower end for all lines are on one curve, defined by the N-points; for the shortest possible expansion route $T_{U}=T_{N}+\delta$ and $T_{L}=T_{N}+\delta$, where $T_{\mathrm{N}}$ refers to the temperature corresponding to point $\mathrm{N}$ and $\delta$ is an infinitesimally small temperature difference with $\delta \rightarrow 0$. For this reason, the lower limit should be located on a straight line with slope $=1$, where $T_{U}=T_{N}=T_{L}$. Marking this lower limit, one can avoid unrealistic $T_{\mathrm{L}}>T_{\mathrm{U}}$ cases.

Materials are identified by their chemical identifier (CAS number). When lines are congested, labels are following the order of lines in zig-zag. Materials corresponding to various classes are plotted in various colors; black for ANCMZ, red for ACNMZ, green for ANZCM and blue for ANCZM; as it was already mentioned, materials with ACNZM sequences have not been found up to now. For additional information, Carnot-efficiencies for a given upper and lower temperature pair are given by color-coded lines. The list of materials with their CAS-number, name, refrigerant code (if any) and classification can be found in Table 1.



Figure 2. Potential isentropic expansion routes on $T_{\mathrm{L}}-T_{\mathrm{U}}$ diagram for 28 working fluids, identified by their CAS-number. Carnot-efficiencies for a given upper and lower temperature pair are given by color-coded lines. 
Since T-s data are available in various sources, NIST-based data (NIST Chemistry Webbook [15] and RefProp 9.1 [16]) has been cross-checked. Visible difference was found only in one occasion (CAS 75-69-4, trichloromonofluoromethane, also called R11 or Freon 11); the alternative curve (data are taken from FluidProp [18], using TPSI model, based on the work of Reynolds [19])) is also plotted by the dashed red line.

Carnot-efficiencies are also shown in Figure 2. These values are characteristic for the given heat source-heat sink pairs. Being the corresponding $T_{\mathrm{U}}$ and $T_{\mathrm{L}}$ values are external constraints, Carnot-efficiencies cannot be improved. They are shown here (and later in similar figures) to give some indication about the theoretical efficiency maximum as a benchmark.

Table 1. List of materials used in the study. The list follows the order of Figure 2 starting at decafluorobutane, marked as 355-25-9 to trichlorofluoromethane (also referred as R11), marked as 75-69-4.

\begin{tabular}{|c|c|c|c|}
\hline CAS-Number & Name & R-Number & Class \\
\hline $355-25-9$ & decafluorobutane & - & ANZCM \\
\hline $76-19-7$ & perfluoropropane & R218 & ANCMZ \\
\hline $76-16-4$ & freon 116 & R116 & ACNMZ \\
\hline $431-89-0$ & propane, 1,1,1,2,3,3,3-heptafluoro- & R227ea & ANCMZ \\
\hline $76-15-3$ & freon 115 & R115 & ACNMZ \\
\hline $431-63-0$ & 1,1,1,2,3,3-hexafluoropropane & R236ea & ANZCM \\
\hline $690-39-1$ & $1,1,1,3,3,3$-hexafluoropropane & R236fa & ACNMZ \\
\hline $107-83-5$ & 2-methylpentane (isohexane) & - & ANCMZ \\
\hline $124-18-5$ & decane & - & ANZCM \\
\hline $111-84-2$ & nonane & - & ANZCM \\
\hline $111-65-9$ & octane & - & ANZCM \\
\hline $142-82-5$ & heptane & - & ANZCM \\
\hline $110-54-3$ & hexane & - & ANZCM \\
\hline $78-78-4$ & 2-methylbutane (isopentane) & R601a & ANCMZ \\
\hline $109-66-0$ & pentane & R601 & ANCMZ \\
\hline 76-13-1 & freon 113 & R113 & ANZCM \\
\hline $75-28-5$ & 2-methylpropane (isobutane) & $\mathrm{R} 600 \mathrm{a}$ & ACNMZ \\
\hline $106-97-8$ & butane & $\mathrm{R} 600$ & ACNMZ \\
\hline $2837-89-0$ & freon 124 & R124 & ACNMZ \\
\hline $679-86-7$ & 1,1,2,2,3-pentafluoropropane & $\mathrm{R} 245 \mathrm{ca}$ & ANCMZ \\
\hline $460-73-1$ & $1,1,1,3,3$-pentafluoropropane & $\mathrm{R} 245 \mathrm{fa}$ & ACNMZ \\
\hline $306-83-2$ & freon 123 & R123 & ACNMZ \\
\hline $110-82-7$ & cyclohexane & - & ANZCM \\
\hline $1717-00-6$ & 1,1-dichloro-1-fluoroethane & $\mathrm{R} 141 \mathrm{~b}$ & ACNMZ \\
\hline $75-68-3$ & ethane, 1-chloro-1,1-difluoro- & $\mathrm{R} 142 \mathrm{~b}$ & ACNMZ \\
\hline $108-88-3$ & toluene & - & ANCMZ \\
\hline $71-43-2$ & benzene & - & ANCZM \\
\hline $75-69-4$ & trichlorofluoromethane & R11 & ACNMZ \\
\hline
\end{tabular}

In the next sections, comparison of $T_{\mathrm{L}}-T_{\mathrm{U}}$ diagram of real materials (where "real" refers to data taken from well-established reference equations) with $T_{\mathrm{L}}-T_{\mathrm{U}}$ diagram of model fluids (van der Waals fluid) is given; this way one might be able to single out erroneous data. Then, the method to find the working fluid which can be used with the simplest layout for a given heat source-heat sink pair by using the $T_{\mathrm{L}}-T_{\mathrm{U}}$ diagram of real fluids is presented.

\section{Comparison of Reduced $T_{\mathrm{L}}-T_{\mathrm{U}}$ Diagrams}

The behaviour of fluids can be described with various equations of states (EoS); usually simple, easily solvable equations are giving less accurate descriptions than more complex, sometimes even non-analytical ones. Luckily, the results given by some of these simple EoS are qualitatively acceptable, therefore they can be applied for comparison purposes. Concerning T-s diagrams, two model fluids has been studied earlier, using van der Waals [8] and Redlich-Kwong [10] EoS. One of the advantages 
of using simple EoS is to reduce the possibility to obtain mathematical artefacts caused by some more accurate, but mathematically more complex EoS (see for example the misplaced second critical point given by the very accurate water EoS, the IAPWS [20]). Therefore, the van der Waals EoS with temperature independent molecular degree of freedom has been used to obtain the "theoretical" $T_{\mathrm{L}}-T_{\mathrm{U}}$ diagram. The result can be seen in Figure 3. Model materials corresponding to various classes are plotted in various colors, also used for Figure 2. Concerning the qualitative agreement mentioned above, it is interesting to see, that the class missing in case of real materials (ACNZM) is also missing here.

One can realize, that the curves are located within a triangle. The lower boundary is defined by the coordinate of the $\mathrm{N}$ points, similarly to Figure 2. Concerning the upper boundary (magenta line), these are the $T_{\mathrm{L}}$ and $T_{\mathrm{U}}$ values for the "longest" expansion lines for classes ACNMZ (red) and ANCMZ (black), namely the points defined by temperatures corresponding to $\mathrm{M}_{\mathrm{S}}^{\mathrm{d}}$ (as $T_{\mathrm{L}}$ ) and $\mathrm{M}$ (as $T_{\mathrm{U}}$ ). The exact shape of this curve is not clarified, but it seems to be close to linear. Concerning the third side of the triangle, it is an artificial limit (therefore it is not marked by a line), caused by the fact that all $T-s$ diagrams of van der Waals fluids have been calculated in the same reduced temperature range (from $T_{\mathrm{r}}=0.3$ to $T_{\mathrm{r}}=1$ ), where the reduced temperature is the actual temperature divided by the critical one. Although this limit seems to be artificial, it reflects correctly, that the "liquid range" of materials located between the triple point and the critical point is usually in the 0.4-1 reduced temperature range for most of the materials [21]. The temperature of these "lowermost points of the liquid state" are identical with the temperatures of point Z (and also with point A), therefore the "longest" expansion lines for classes ANCZM (blue) and ANZCM (green), are terminated on a line formed by the upper and lower expansion end-points, defined by temperatures corresponding to $\mathrm{Z}\left(\right.$ as $\left.T_{\mathrm{L}}\right)$ and $\mathrm{Z}_{\mathrm{s}}^{\mathrm{u}}\left(\right.$ as $\left.T_{\mathrm{U}}\right)$.

For comparison, the reduced $T_{\mathrm{L}}-T_{\mathrm{U}}$ diagram for the real materials (shown in Figure 2) can be seen in Figure 4. The real curves are also located in a triangular region. The lower border is as sharp as before, because it is the slope $=1$ line, defined by the identical $T_{U}$ and $T_{L}$ temperatures of points $N$. One can also see an upper boundary defined by temperatures corresponding to $M_{s}^{d}$ (as $T_{L}$ ) and $M$ (as $T_{\mathrm{U}}$ ). While for the model fluid, this upper boundary for ANCMZ (black) and ACNMZ (red) classes is quite sharp, one can see that it is less defined here. Concerning the third side of the region, it can be noted that the expansion line for most of the materials in the ANZCM class (green) terminate in the reduced $T_{\mathrm{L}}=0.35-0.4$ region (as it is "expected" from the thumb-rule between melting and critical temperatures, see for example [21]), but the remaining part of the ANZCM-class materials as well as the only ANCZM-one terminate at higher reduced $T_{U}$ temperatures, showing much narrower liquid region between freezing and critical point.

Concerning trichlorofluoromethane (CAS 75-69-4), which has a different representation using NIST-based data or Stanford (TPSI)-based data, it seems that both curves are too short (they terminate much below the upper boundary), but the TPSI-data seems to be better. For other materials, no visible differences have been found. From the data obtained by van der Waals EoS, one can see the existence of an upper envelope of the curves. Therefore, one can expect that for real materials, the curves will also be confined between an upper and a lower borderline. It means that for example shorter expansion lines of ACNMZ class fluids should be located on higher $T_{\mathrm{L}, \mathrm{r}}$ temperatures, than longer expansion lines. Hence, the short solid line representing trichlorofluoromethane (R11, 75-69-4) is probably misplaced and it should be located above the expansion line of freon-116 (76-16-4) and not below it. Consequently, the dashed red lines based on TPSI-data seems to be better than the one, based on NIST data.

On one hand, by using reduced temperature data, the structure of $T_{\mathrm{L}}-T_{\mathrm{U}}$ diagram are much clearer now; also it can help to single out erroneous data. On the other hand, for the selection of the optimal working fluid for a given heat source- - heat sink, the use of the original $T_{\mathrm{L}}-T_{\mathrm{U}}$ diagram is necessary, as it will be shown in the next section. 


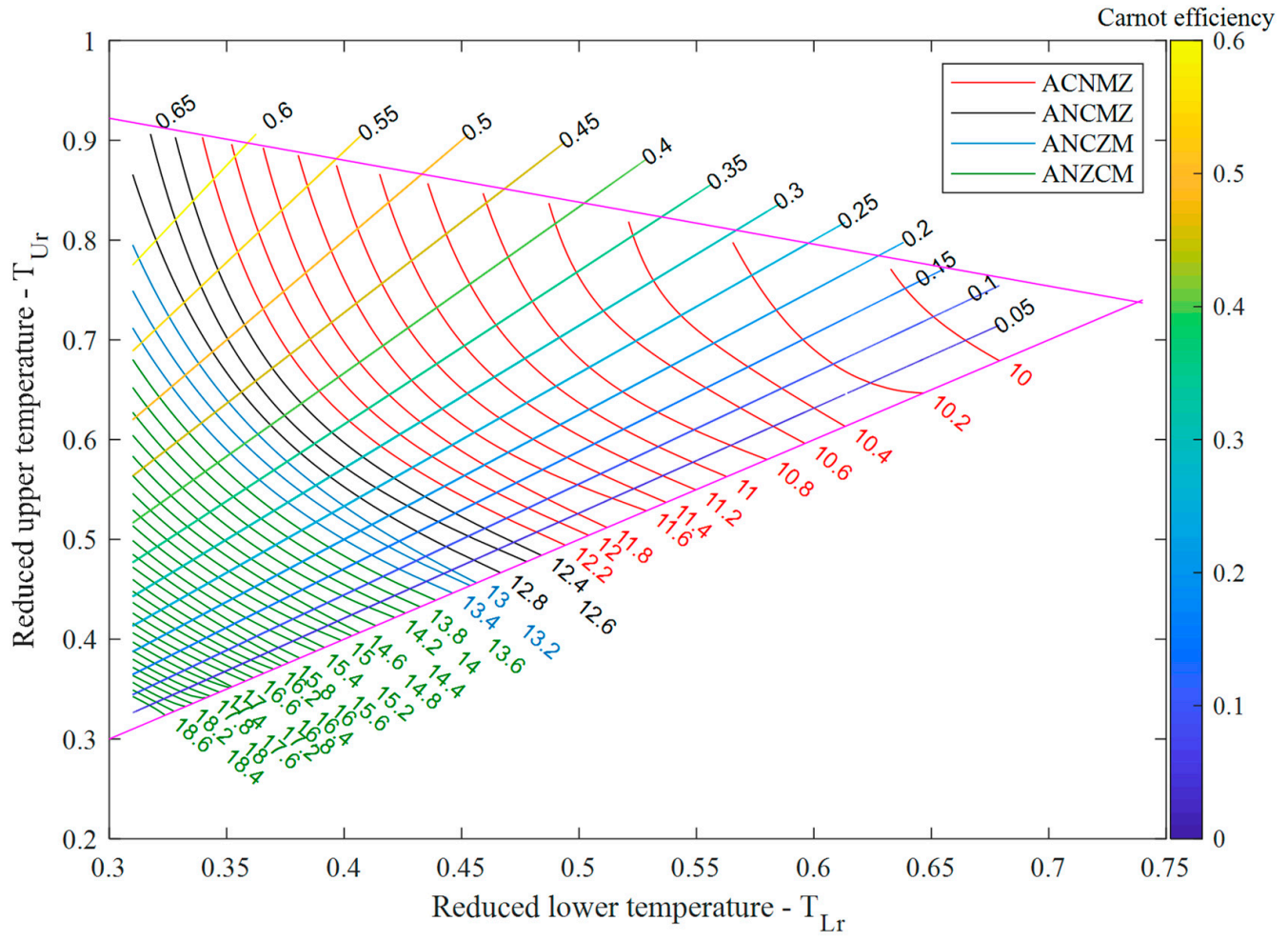

Figure 3. Potential isentropic expansion routes on $T_{\mathrm{L}}-T_{\mathrm{U}}$ diagram for van der Waals model fluids. Molecular degree of freedom are marked for each curves at the bottom. Carnot-efficiencies for a given upper and lower temperature pair are given by color-coded lines with numerical values on the top.

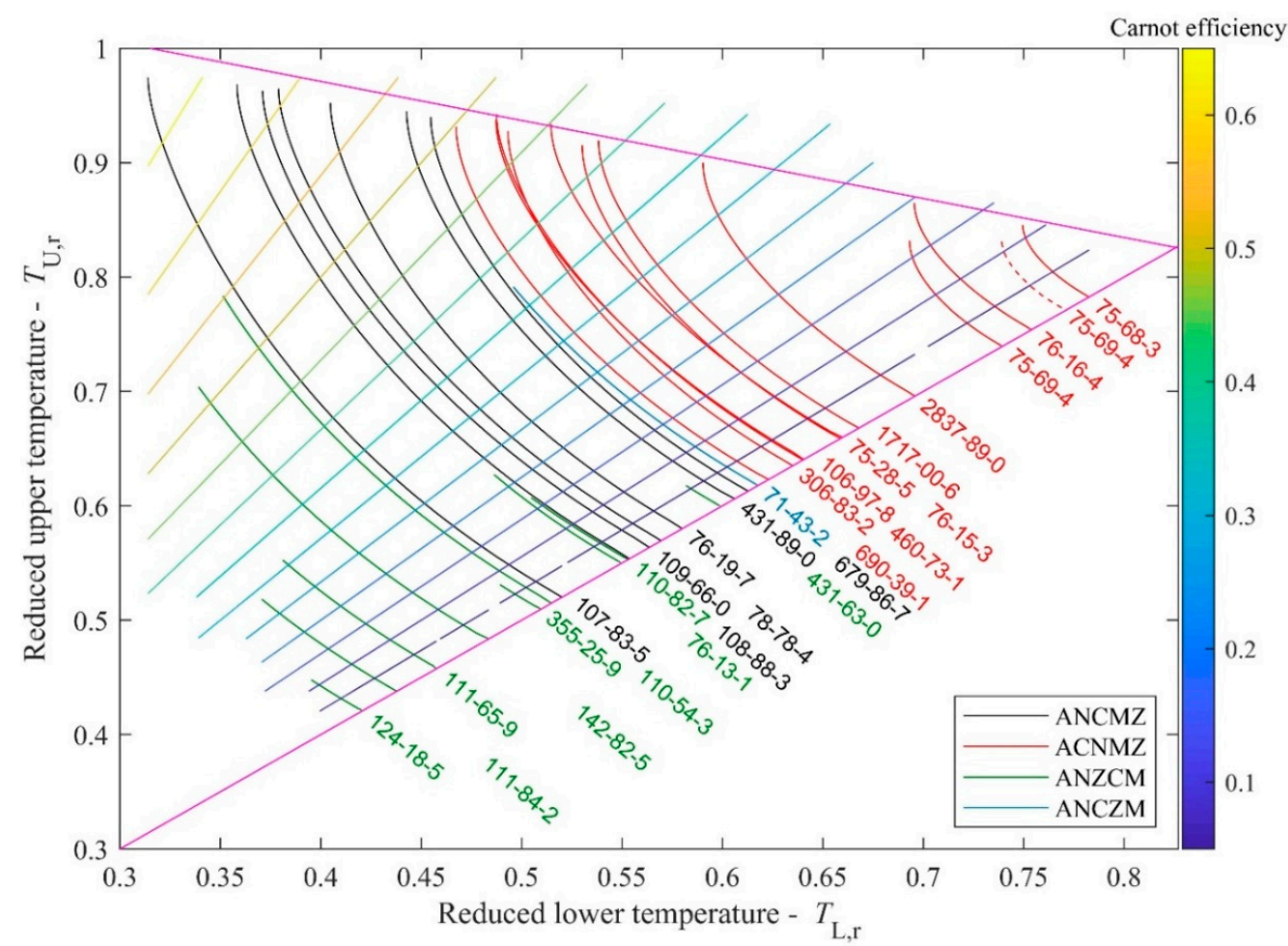

Figure 4. Potential isentropic expansion routes in a reduced $T_{\mathrm{L}}-T_{\mathrm{U}}$ diagram of 28 working fluids, identified by their CAS-numbers. Carnot-efficiencies for a given upper and lower temperature pair are given by color-coded lines. 


\section{Selection Process of the Thermodynamically Optimal Working Fluid}

Concerning an existing heat reservoir, one has to use a fixed maximal or upper temperature $\left(T_{U}\right)$ for the cycle, given by the heat source temperature $\left(T_{\text {source }}\right)$ and the pinch temperature $(\Delta T$, a characteristic value for the heat exchanger) as:

$$
T_{\mathrm{U}}=T_{\text {source }}-\Delta T
$$

In a similar manner, the lowest temperature of the cycle $\left(T_{\mathrm{L}}\right)$ can be defined by the temperature of the environment used for cooling $\left(T_{\text {environment }}\right)$ and a lower pinch temperature (not necessarily equal with the other one) as:

$$
T_{\mathrm{L}}=T_{\text {environment }}+\Delta T
$$

This $\left(T_{\mathrm{U}} ; T_{\mathrm{L}}\right)$ pair can be used as a characteristic point in Figure 2 to represent a given heat source and sink with other technical details such as quality of heat exchangers; since for reduced quantities, the critical temperature of the working fluid is also necessary, therefore on reduced diagrams (like Figure 3), the reduced $\left(T_{U} ; T_{L}\right)$ points alone cannot be used to characterize the heat source and heat sink of the system.

In Figure $5 \mathrm{~d}$, the grey cross represents a hypothetical heat source and sink characterized by $T_{\mathrm{U}}=293 \mathrm{~K}=19.85{ }^{\circ} \mathrm{C}$ and $T_{\mathrm{L}}=393 \mathrm{~K}=119.85^{\circ} \mathrm{C}$. This can be for example a geothermal heat reservoir with a natural cold water source (a small river) or cold internal air (winter) used for cooling. This situation is very similar to the first (and presently only) ORC-based Hungarian geothermal power plant (see the ORC Word Map [22]).

In Figure 5d, only part of the data presented in Figure 2 can be seen, centered on the (293K, $393 \mathrm{~K})$ point. This point is located between two lines representing two working fluids, namely benzene (CAS 71-43-2) and toluene (CAS 108-88-3); one more material can be seen here, namely the 1,1-dichloro-1-fluoroethane (CAS 1717-00-6, also referred as R141b). Since none of these lines run through the 293-392 K point, the closest ones (benzene and toluene) should be considered as nearest to ideal. For the sake of completeness, the potential use of the third one (R141b) is also discussed. The upper and lower temperatures determine the extent of expansion, as it can be seen in Figure $5 \mathrm{a}$,e (benzene), Figure 5b,f (toluene) and Figure 5c,g (R141b).

For further discussion, one can define the so-called quality $(q)$, also referred as dryness or dryness fraction of pure fluids, representing the ratio of vapour within the two-phase region and defined as:

$$
q=\frac{n^{v}}{n^{l}+n^{v}}
$$

where $n^{v}$ and $n^{l}$ are the mole- (or alternatively, the mass-) fraction of the fluid in the vapour or liquid phase, respectively. This quality can change between one (saturated vapour) and zero (saturated liquid); outside of the two-phase region, it is usually not defined or defined as one (vapour states) or zero (liquid states). This ratio can be also calculated by using the specific entropy values for the given mixed state and comparing it with the entropy values of the saturated liquid and vapour states at the same temperature [23].

In the case of benzene (Figure 5a,e), one can see that the expansion route started at saturated vapour state at $393 \mathrm{~K}$ and terminated at $293 \mathrm{~K}$, runs in superheated dry vapour region for a while, but the final part of the expansion (starting from $309.96 \mathrm{~K}$ down to $293 \mathrm{~K}$, i.e., in an almost $17 \mathrm{~K}$ temperature range) runs into the two-phase, wet region. The maximal $q$ value (corresponding to the final state of the expansion) is 0.9848 , equal to $1.52 \%$ (in mass) of droplet. Droplets may cause erosion problems, moreover they might decrease the net efficiency due to moisture loss, although this $1.52 \%$ is not very high compared to the $8-12 \%$ which is usually considered tolerable [24]. For benzene, the ideal case-i.e., expansion from one saturated vapour state to another saturated vapour state-would be the termination of expansion at $T_{\mathrm{L}}=309.96 \mathrm{~K}$, given by the cross section of the blue line (representing 
benzene) and grey dashed line (representing $T_{\mathrm{U}}=393 \mathrm{~K}$ ). Stopping at this higher temperature would cause smaller efficiency, therefore the problem of droplet erosion should be weighed against the problem of potential efficiency loss, before deciding the use or omission of benzene. It also means that benzene would be the ideal working fluid (concerning only the expansion route and neglecting other selection criteria) for a heat source and sink characterized by $\left(T_{U}, T_{\mathrm{L}}\right)=(393 \mathrm{~K}, 309.96 \mathrm{~K})$ temperatures.


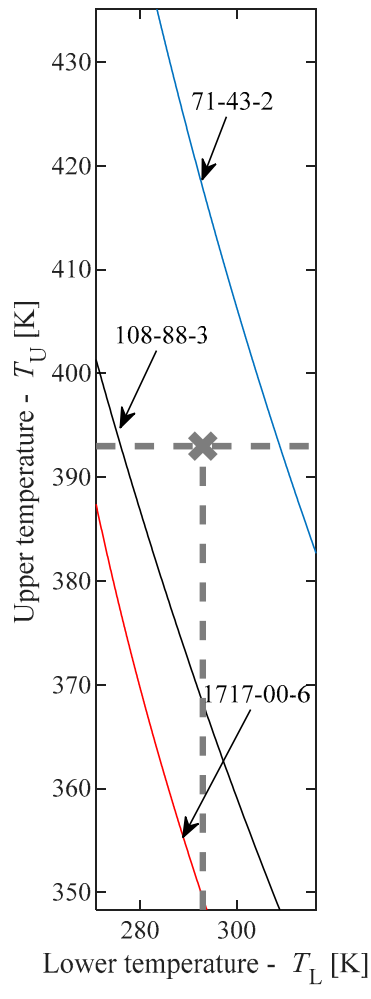

(d)
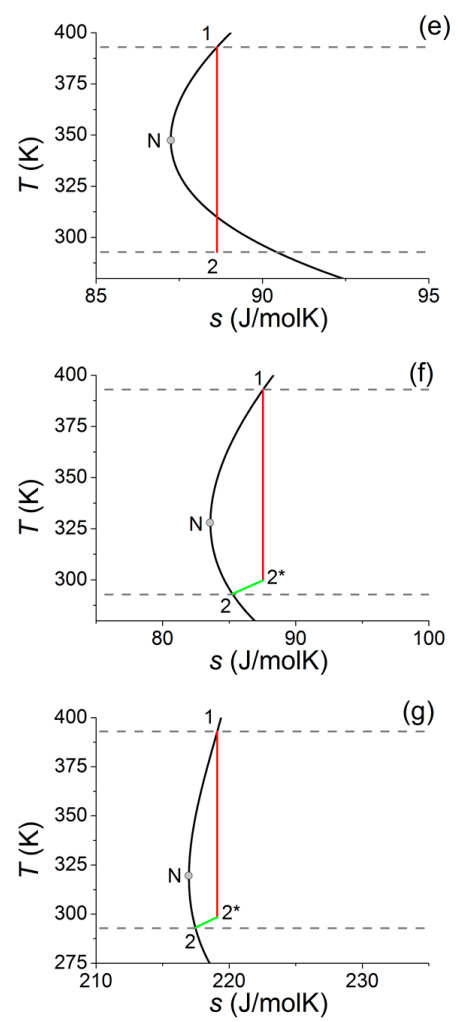

Figure 5. Expansion process of benzene, CAS 71-43-2 (a,e), toluene, CAS 108-88-3 (b,f) and 1,1-dichloro-1-fluoroethane, also referred as R141b or CAS 1717-00-6 (c,g) for a given $T_{\mathrm{L}}-T_{\mathrm{U}}$ pair (293-393 K). Magnified part of Figure 2 centered on the 293-393 K point can be seen in the middle (d), representing benzene (blue), toluene (black) and R141b (red). Right-side figures (e-g) show the magnified parts of $(\mathbf{a}-\mathbf{c})$ around point $\mathrm{N}$, for the better visibility of the expansion lines.

In case of toluene (Figure $5 b, f$ ) if the expansion route starts at saturated vapour state at $393 \mathrm{~K}$ and terminates at $293 \mathrm{~K}$, than even the final part of the expansion runs in superheated dry vapour states. Therefore one would not face challenges regarding droplet formation. Unfortunately, another problem emerges, namely the problem of cooling down the expanded dry vapour in an isobaric way before reaching saturated vapour state at $T_{\mathrm{L}}=293 \mathrm{~K}$. Therefore, isentropic expansion (solid red line) has to be stopped at a higher temperature (point $2^{*}, \mathrm{~T}=299.7 \mathrm{~K}$ ) and the rest of the process $\left(2^{*} \rightarrow 2\right)$ has to proceed on an isobaric cooling route (green line). In this way, a small, almost triangle shaped part in the T-s diagram (formed by the grey line, the green line and by the extension of the red one) will be excluded from the cycle, decreasing the thermal efficiency. As an additional problem, this unused (lost) heat can increase the heat-load of the environment. Addition of a recuperative heat exchanger to the system can solve-or at least minimize - these problems, since part of this heat can be used to pre-heat the compressed liquid. This solution is appropriate only if the temperature difference between point $2^{*}$ and 2 is large enough. In case of toluene with 393-293 K expansion, this gap is around $\Delta T=7 \mathrm{~K}$, which can be used only in a very limited manner for this purpose. With a larger gap, this heat can be utilized better, however the thermal efficiency is still smaller, therefore the goal remains to reach a perfect "saturated steam to saturated steam" expansion route, with zero gap. Similarly to the case of benzene, one can define an ideal $T_{\mathrm{L}}$, where 
expansion from $T_{U}$ would be terminated at the saturated vapour state; for toluene it would be $276.06 \mathrm{~K}$. It means, that toluene would be the ideal working fluid (concerning expansion route) for a heat source and sink characterized by $\left(T_{\mathrm{U}}, T_{\mathrm{L}}\right)=(393 \mathrm{~K}, 276.06 \mathrm{~K})$ temperatures.

In case of R141b (Figure $5 c, g$ ) the situation is very similar to the one observed for toluene. The expansion- even in the final stage-runs in superheated dry vapour region, so droplet-related problems do not exist. Similarly to toluene, isentropic expansion has to be stopped at a temperature above $293 \mathrm{~K}$, namely at the one marked as $2^{*}$ (here it means $298.5 \mathrm{~K}$ ) and the rest of the process $\left(2^{*} \rightarrow 2\right)$ has to proceed on an isobaric cooling route, losing some part of thermal efficiency and increasing the heat-load of the environment. Here, the temperature gap between points $2^{*}$ and 2 is $5.5 \mathrm{~K}$, which is probably too small to use recuperator. Similarly to the case of benzene and toluene, one can define an ideal $T_{\mathrm{L}}$, where expansion from $T_{\mathrm{U}}$ would be terminated at the saturated vapour state; for R141b it would be $268.2 \mathrm{~K}$, almost $8 \mathrm{~K}$ lower than for toluene. It means, that R141b would be the ideal working fluid (concerning expansion route) for a heat source and sink characterized by $\left(T_{\mathrm{U}}, T_{\mathrm{L}}\right)=(393 \mathrm{~K}, 268.2 \mathrm{~K})$ temperatures. One should realize, that for materials on the dry side, but "farther" from the point characterizing the heat source and heat sink (here, toluene is closer, R141b is farther), the expansion has to be stopped farther on temperature scale from the saturated liquid state, but this temperature distance does not correlate with the temperature difference between points $2^{*}$ and 2 . For R141b, the "belly" of the inverse S-shape is smaller than for toluene, therefore the temperature gap between points $2^{*}$ and 2 is smaller for R141b than for toluene, despite the fact that R141b is farther from the characteristic point. Therefore, R141b might be better for this given heat source and heat sink system, than for toluene, i.e., not only the immediate, but second (or even further) neighbours should be checked in the selection process.

Table 2 summarizes the data which compares the efficiencies of cycles using various materials. Details of the calculations are given in the Supplementary Materials. For all materials, the total efficiencies are in the $21.05-21.72 \%$, and the net efficiencies are in the $20.79-21.66 \%$ range. With such small differences - especially for benzene and toluene-the difference of operational (including maintenance) and investment costs by using the simplest layout can be a decisive factor by choosing working fluids. In this case-since the ideal fluid has not been found-the cost related to the presence of droplets has to be compared with the costs related to the installation and operation of the recuperator. Since the use of recuperator are not justified here, toluene seems to be the better choice in the given temperature range; its net efficiency matches the efficiency of benzene but droplets would not be present to cause erosion-related problems. Obviously, using other parameters for the optimization process, other fluids might perform better.

Table 2. Total $\left(\eta_{\text {br }}\right)$ and net $\left(\eta_{\text {net }}\right)$ cycle efficiencies-calculated in CycleTempo 5.0 environment using fluid data from RefProp 9.0- of ORCs using working fluids presented in Figures 5 and 6. For net efficiencies, self-consumption of pumps were deducted. Temperatures are shown here not only in K, but also in Celsius, according to engineering practice. Values for qualities at the end of expansion are also shown $(q)$. Details of calculations can be seen in Supplementary materials.

\begin{tabular}{ccccccc}
\hline \multirow{2}{*}{$T_{\mathrm{L}}$} & $19.85{ }^{\circ} \mathrm{C}$ & $19.85{ }^{\circ} \mathrm{C}$ & $19.85{ }^{\circ} \mathrm{C}$ & $-44.65{ }^{\circ} \mathrm{C}$ & $-44.65{ }^{\circ} \mathrm{C}$ & $-44.65{ }^{\circ} \mathrm{C}$ \\
& $293 \mathrm{~K}$ & $293 \mathrm{~K}$ & $293 \mathrm{~K}$ & $228.5 \mathrm{~K}$ & $228.5 \mathrm{~K}$ & $228.5 \mathrm{~K}$ \\
\hline \multirow{2}{*}{$T_{\mathrm{U}}$} & $119.85{ }^{\circ} \mathrm{C}$ & $119.85{ }^{\circ} \mathrm{C}$ & $119.85{ }^{\circ} \mathrm{C}$ & $29.85{ }^{\circ} \mathrm{C}$ & $29.85{ }^{\circ} \mathrm{C}$ & $29.85{ }^{\circ} \mathrm{C}$ \\
& $393 \mathrm{~K}$ & $393 \mathrm{~K}$ & $393 \mathrm{~K}$ & $303 \mathrm{~K}$ & $303 \mathrm{~K}$ & $303 \mathrm{~K}$ \\
\hline material & benzene & toluene & R141b & pentane & isopentane & hexane \\
\hline CAS & $71-43-2$ & $108-88-3$ & $1717-00-6$ & $109-66-0$ & $78-78-4$ & $110-54-3$ \\
\hline \multirow{2}{*}{ br } & $21.72 \%$ & $21.65 \%$ & $21.05 \%$ & $21.23 \%$ & $21.21 \%$ & $21.28 \%$ \\
\hline net & $21.66 \%$ & $21.63 \%$ & $20.79 \%$ & $21.21 \%$ & $21.18 \%$ & $21.27 \%$ \\
\hline$P_{\text {pump }}$ & $-2.75 \mathrm{~kW}$ & $-1.26 \mathrm{~kW}$ & $-12.55 \mathrm{~kW}$ & $-1.04 \mathrm{~kW}$ & $-1.46 \mathrm{~kW}$ & $-0.31 \mathrm{~kW}$ \\
\hline$P_{\text {turb }}$ & $1000 \mathrm{~kW}$ & $1000 \mathrm{~kW}$ & $1000 \mathrm{~kW}$ & $1000 \mathrm{~kW}$ & $1000 \mathrm{~kW}$ & $1000 \mathrm{~kW}$ \\
\hline$q$ & $98.48 \%$ & $100.00 \%$ & $100.00 \%$ & $99.52 \%$ & $100.00 \%$ & $100.00 \%$ \\
\hline
\end{tabular}


Unfortunately, none of the expansion routes of known working fluids run through the (393 K, $293 \mathrm{~K})$ point, therefore one can choose only something "close enough". Another alternative would be-especially when there are two "close enough" working fluids with chemically similar structure, like toluene and benzene- the application of a mixture. Due to the chemical similarity, the mixture would be probably an almost ideal, zeotropic mixture, which can be used more easily as working fluid in ORC applications than azeotropic ones $[8,25,26]$.
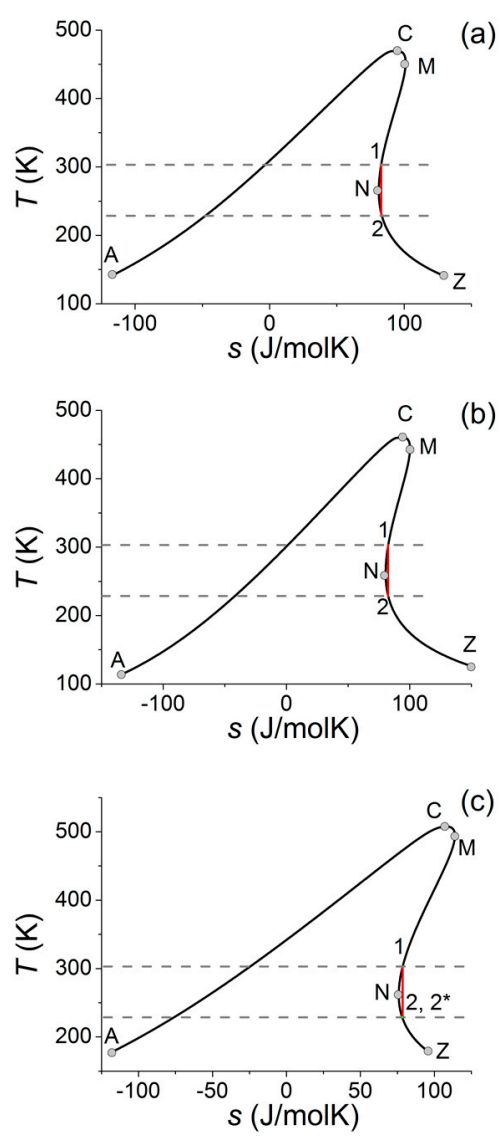

(a)

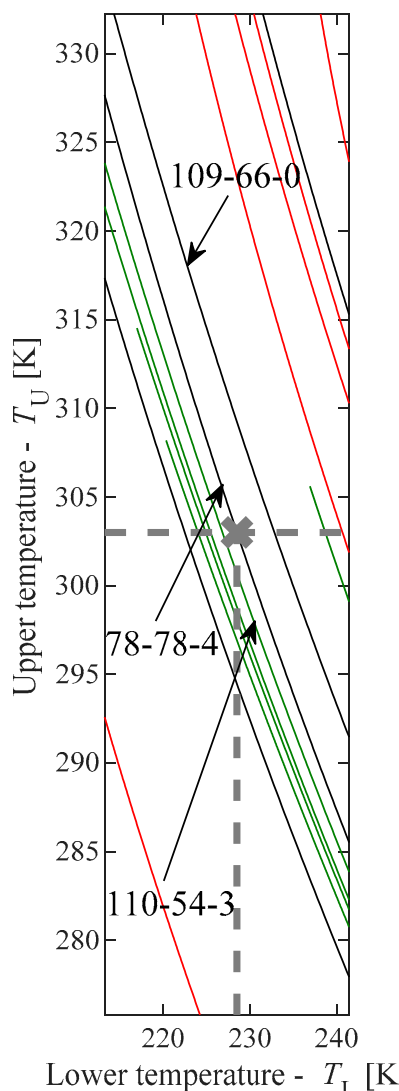

(d)
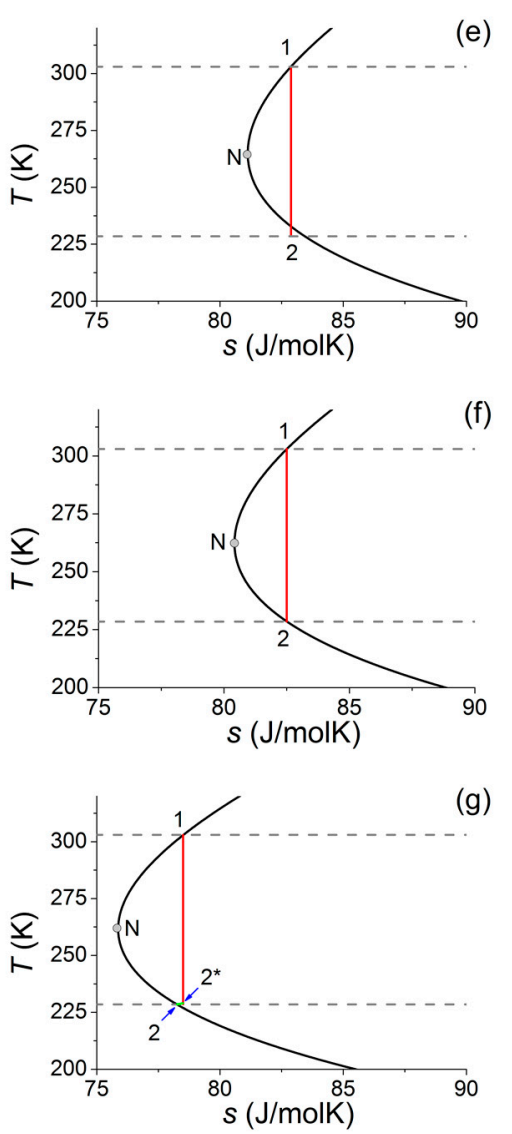

Figure 6. Expansion process for pentane (CAS 109-66-0) (a,e), 2-methylbutane (CAS 78-78-4) (b,f) and hexane (CAS 110-54-3) $(\mathbf{c}, \mathbf{g})$ for a given $T_{\mathrm{L}}-T_{\mathrm{U}}$ pair $(228.5 \mathrm{~K}, 303 \mathrm{~K})$ ). The magnified part of Figure 2 centered on the $228.5-303 \mathrm{~K}$ point can be seen in the middle (d), representing the expansion routes for pentane black), 2-methylbutane (black) and hexane (green). Right-side figures (e-g) show the magnified parts for $(\mathbf{a}-\mathbf{c})$ diagrams, for the better visibility of the expansion lines.

Concerning lower temperatures, one can see regions on the $T_{\mathrm{U}}-T_{\mathrm{L}}$ diagram densely packed with expansion routes. Recently, there are more and more applications for liquid methane (LNG). LNG can be transported to LNG-terminals by ships, and there they must be re-gasified before injected into the regular gas network, giving the possibility to utilize the so-called "cold energy" $[27,28]$. Concerning the fact, that the temperature of liquid methane can be as low as $111 \mathrm{~K}\left(-162^{\circ} \mathrm{C}\right)$, the external heat used for re-gasification can be even the environmental heat (air, water), around or below $300 \mathrm{~K}$. Obviously, going down to $111 \mathrm{~K}$ in an ORC would cause some serious problems concerning materials used for the construction, but using the methane as heat sink and cooling the chosen working fluid down only to a moderate level, one can define an acceptable expansion range for example between $T_{U}=303 \mathrm{~K}$ and $T_{\mathrm{L}}=228.5 \mathrm{~K}$. Here, the lower temperature is only an arbitrarily chosen, but plausible value to demonstrate the selection process; for any other temperature, the selection process would be the same, only the optimal working fluid would be different. In Figure 6d, one can see part of Figure 2 centered 
around this point. It is clearly visible, that one line runs almost exactly through this point, namely the line representing 2-methylbutane (isopentane, CAS 78-78-4) and it is slightly off from the lines representing two linear alkanes, hexane (CAS 110-54-3) and pentane (CAS 109-66-0). Expansion lines for these three working fluids are shown in Figure $6 \mathrm{a}, \mathrm{e}$ (pentane), Figure $6 \mathrm{~b}, \mathrm{f}(2$-methylbutane) and Figure 6c,g (hexane).

First, the potential use of pentane is discussed. In this case, the end of the expansion runs into the two-phase (wet) region (see Figure 6a,e), but in a much smaller extent, than it was shown for benzene. Here, the expansion line enters the two-phase region around $232.8 \mathrm{~K}$, only $4.3 \mathrm{~K}$ above the end of the expansion process. The quality of wet steam will be 0.9952 , corresponding to $0.48 \%$ wetness, half of the value reported in the previous case. In the case of benzene, the wetness was already in the tolerable level; it is even more valid for this case.

By using 2-methylbutane, the expansion between $T_{\mathrm{U}}=303 \mathrm{~K}$ and $T_{\mathrm{L}}=228.5 \mathrm{~K}$ starts and terminates in saturated vapour states, avoiding all problem related to wet or superheated dry vapour. This is shown in Figure $6 \mathrm{~b}, \mathrm{f}$. Concerning the expansion route, this is the perfect working fluid for a heat source and heat sink pair, represented by $T_{\mathrm{U}}=303 \mathrm{~K}$ and $T_{\mathrm{L}}=228.5 \mathrm{~K}$.

Finally, the use of hexane is discussed. In this case, the expansion should be terminated within the dry vapour region and the working fluid has to be cooled down to $T_{\mathrm{L}}$ by isobaric cooling. Here, the isobaric part is so small, that it can be hardly seen even on the magnified figure (Figure $6 c, g$ ); the expansion has to stop at $228.97 \mathrm{~K}$, instead of $228.5 \mathrm{~K}$, only $0.47 \mathrm{~K}$ above the $T_{\mathrm{L}}$. This small gap cannot be utilized for pre-heating the pressurized liquid, but the heat loss caused by this part is negligible.

For these materials, total cycle efficiencies move in the very narrow $21.21-21.28 \%$ range, while their net counterparts are in the $21.18-21.27 \%$ range. With such small differences, the difference of operational and investment costs by using the most simple layout can be a decisive factor by choosing working fluids; in this case, the most simple layout can be realized by using 2-methylbutane, without the loss of efficiency. Obviously, other parameters of optimization might give a different result, but for our criteria, this is the best-performing working fluid for the given temperature range. It should be noted here, that being the three materials chemically similar, some of their chemistry-related properties (like ODP, GWP, toxicity, flammability) are quite similar, and therefore the indicators related to these properties are also similar.

In the case of $T_{\mathrm{U}}=303 \mathrm{~K}$ and $T_{\mathrm{L}}=228.5 \mathrm{~K}$, one can pinpoint the ideal working fluid, where expansion would run from one saturated vapour state to another saturated vapour state, all along a dry vapour route. At the end of the expansion, the final state would be a saturated vapour state, therefore the problems caused by wet or superheated dry vapour (discussed above) do not exist! This ideal working fluid would be the 2-methylpentane. Due to the fact that expansion routes for several materials run in the immediate vicinity of this $\left(T_{U}, T_{L}\right)=(228.5 \mathrm{~K}, 303 \mathrm{~K})$ point, one can even find a second-, third-, fourth-best; this is especially important, when the working fluid chosen as "best" for our criterion performs worse, when another important optimization criterion is considered. Because these routes are close to our working point, using one of them-instead of the ideal one-would cause only minor problems, acceptable for the given application. For this temperature range, the ones next to the best would be pentane and hexane; using them the problems caused by the presence of droplets or superheated dry vapour are almost negligible, therefore their application (and probably the application of several other working fluids with expansion range lines running close to the $\left(T_{U}\right.$, $\left.\left.T_{\mathrm{L}}\right)=(228.5 \mathrm{~K}, 303 \mathrm{~K})\right)$ would be acceptable. In this way, one could use other criteria (environmental safety, chemical compatibility, price, availability, etc.) together with some optimization method (see for example [29-31]) to choose the proper working fluid, still acceptable thermodynamically, but not necessarily the best one according to this criterion.

\section{Conclusions}

A novel method has been proposed to choose the best working fluid-from the point of view of expansion route-for a given heat source and heat sink (characterized by a maximum and minimum 
temperature). The method is based on the novel classification of working fluids using the sequences of their characteristic points on temperature-entropy space [11]. Using this simple method, a possible expansion route can be defined between an upper and lower temperature values; these temperatures are characterizing the given heat source, heat sink and the set of heat exchangers. In this way, one can select a working fluid (from a database, see [14]), where an ideal adiabatic (isentropic) expansion process between a given upper and lower temperature is possible in a way, that the initial and final states are both saturated vapour states and the ideal (isentropic) expansion line runs in the superheated dry vapour region all along the expansion. In this way, it is possible to avoid problems related to the presence of droplets or superheated dry steam in the final expansion state, just before the condensation. Therefore, one can use the most simple ORC layout, using only a pump, two heat exchangers (evaporator, condenser) and an expander, avoiding the use of superheater (or droplet separator) and recuperator; since the fluid is always in dry condition during expansion, droplet erosion can also be avoided.

Study of potential expansion routes in van der Waals model fluids and comparison of the results with the one obtained with real working fluids can help us to single out erroneous data of working fluids presented in various databases.

Presently we have a database of nearly 30 pure fluids with T-s data taken from the NIST Chemistry WebBook [15] and from RefProp 9.1 [16]. Most of these fluids were termed formerly as "dry", while in the novel classification they are in various isentropic sub-classes, namely in ANCMZ, ACNMZ, ANZCM and ANCZM. Due to the fact, that the characteristic point responsible for the existence of these expansion routes (point $\mathrm{N}$ ) is usually located at low temperature for most of the materials of our database, presently this method with the existing, highly accurate database can mostly be used to choose the working fluids thermodynamically most suitable for cryogenic cycles (applied for example for heat recovery during LNG-regasification, see for example [27,28], although some of the materials can be used in higher temperatures (covering part of the temperature range for geothermal and waste heat utilization).

Extension of the method (including internal efficiencies below 1 for the expander as well as acceptable wetness for the final vapour state) and expansion of the database with more material are in progress. After a proper extension of the database, this method will be available to choose ideal working fluids for other temperatures (like the ones characteristic for various geothermal or waste heat applications).

Supplementary Materials: The following are available online at http://www.mdpi.com/1996-1073/12/10/2028/s1, "Cycle efficiencies of ORCs using working fluids presented in Figures 5 and 6".

Author Contributions: Conceptualization, A.R.I.; analysis: R.K. and A.G; writing: A.R.I., A.G. and R.K.

Funding: This work was performed in the frame of FIEK_16-1-2016-0007 project, implemented with the support provided from the National Research, Development and Innovation Fund of Hungary, financed under the FIEK_16 funding scheme. Some part of the research reported in this paper was supported by the Higher Education Excellence Program of the Ministry of Human Capacities in the frame of Nanotechnology research area of Budapest University of Technology and Economics (BME FIKP-NANO) Partial financial supports of the Hungarian National Innovation Office grant (NKFIH, grant No. K116375) is also acknowledged

Conflicts of Interest: The Authors declare no conflict of interest.

\section{References}

1. Macchi, E.; Astolfi, M. Organic Rankine Cycle (ORC) Power Systems: Technologies and Applications; Elsevier-Woodhead Publishing: Duxford, UK, 2016.

2. Blaise, M.; Feidt, M. Waste Heat Recovery and Conversion into Electricity: Current Solutions and Assessment. Int. J. Thermodyn. 2019, 22, 1-7. [CrossRef]

3. Chen, H.; Goswami, D.Y.; Stefanakos, E.K. A review of thermodynamic cycles and working fluids for the conversion of low-grade heat. Renew. Sustain. Energy Rev. 2010, 14, 3059-3067. [CrossRef] 
4. Bao, J.; Zhao, L. A review of working fluid and expander selections for Organic Rankine Cycle. Renew. Sustain. Energy Rev. 2013, 24, 325-342. [CrossRef]

5. Zhang, X.; He, M.; Wang, J. A new method used to evaluate organic working fluids. Energy 2014, 67, 363-369. [CrossRef]

6. Xia, X.X.; Wang, Z.Q.; Hu, Y.H.; Zhou, N.J. A novel comprehensive evaluation methodology of organic Rankine cycle for parameters design and working fluid selection. Appl. Therm. Eng. 2018, 143, $283-292$. [CrossRef]

7. Garrido, J.M.; Quinteros-Lama, H.; Mejía, A.; Wisniak, J.; Segura, S. A rigorous approach for predicting the slope and curvature of the temperature-entropy saturation boundary of pure fluids. Energy 2012, 45, 888-899. [CrossRef]

8. Groniewsky, A.; Györke, G.; Imre, A.R. Description of wet-to-dry transition in model ORC working fluids. Appl. Therm. Eng. 2017, 125, 963-971. [CrossRef]

9. Albornoz, J.; Mejía, A.; Quinteros-Lama, H.; Garrido, J.M. A rigorous and accurate approach for predicting the wet-to-dry transition for working mixtures in organic Rankine cycles. Energy 2018, 156, 509-519. [CrossRef]

10. Groniewsky, A.; Imre, A.R. Prediction of the ORC working fluid's temperature-entropy saturation boundary using Redlich-Kwong equation of state. Entropy 2018, 20, 93. [CrossRef]

11. Györke, G.; Deiters, U.K.; Groniewsky, A.; Lassu, I.; Imre, A.R. Novel Classification of Pure Working Fluids for Organic Rankine Cycle. Energy 2018, 145, 288-300. [CrossRef]

12. White, J.A.; Velasco, S. Characterizing wet and dry fluids in temperature-entropy diagrams. Energy 2018, 154, 269-276. [CrossRef]

13. White, J.A.; Velasco, S. A Simple Semiempirical Method for Predicting the Temperature-Entropy Saturation Curve of Pure Fluids. Ind. Eng. Chem. Res. 2019, 58, 1038-1043. [CrossRef]

14. Györke, G.; Groniewsky, A.; Imre, A.R. A simple method to find new dry and isentropic working fluids for Organic Rankine Cycle. Energies 2019, 12, 480. [CrossRef]

15. NIST Chemistry WebBook, NIST Standard Reference Database Number 69. 2018. Available online: http://webbook.nist.gov/chemistry/ (accessed on 1 December 2018).

16. RefProp 9.1. 2013. Available online: https://www.nist.gov/srd/refprop (accessed on 1 December 2018).

17. Imre, A.R.; Groniewsky, A. Various ways of adiabatic expansion in Organic Rankine Cycle (ORC) and in Trilateral Flash Cycle (TFC). Z. Phys. Chem. 2019, 233, 577-594. [CrossRef]

18. FluidProp version 3.0.4. 2016. Available online: http://www.asimptote.nl/software/fluidprop/ (accessed on 1 December 2018).

19. Reynolds, W.C. Thermodynamic Properties in S.I.: Graphs, Tables, and Computational Equations for Forty Substances; Department of Mechanical Engineering, Stanford University: Stanford, CA, USA, 1979.

20. Imre, A.R.; Groniewsky, A.; Györke, G. Description of the metastable liquid region with quantic and quasi-quintic equation of states. Interfacial Phenom. Heat Transf. 2017, 5, 173-185. [CrossRef]

21. Taft, R.; Stareck, J. Relationship between Melting-Points, Normal Boiling-Points and Critical Temperatures. J. Phys. Chem. 1930, 34, 2307-2317. [CrossRef]

22. ORC World Map. 2019. Available online: https://orc-world-map.org/ (accessed on 1 December 2018).

23. Imre, A.R.; Quinones-Cisneros, S.E.; Deiters, U.K. Adiabatic processes in the liquid-vapor two-phase region-1. Pure fluids. Ind. Eng. Chem. Res. 2014, 53, 13529-13542. [CrossRef]

24. Bassily, A.M. Modeling, numerical optimization, and irreversibility reduction of a dual-pressure heat combined-cycle. Appl. Energy 2005, 81, 127-151. [CrossRef]

25. Su, W.; Hwang, Y.; Deng, S.; Zhao, L.; Zhao, D. Thermodynamic performance comparison of Organic Rankine Cycle between zeotropic mixtures and pure fluids under open heat source. Energy Convers. Manag. 2018, 165, 720-737. [CrossRef]

26. Varga, Z.; Csaba, T. Techno-economic evaluation of waste heat recovery by organic Rankine cycle using pure light hydrocarbons and their mixtures as working fluid in a crude oil refinery. Energy Convers. Manag. 2018, 174, 793-801. [CrossRef]

27. Sadaghiani, M.S.; Ahmadi, M.H.; Mehrpooya, M.; Pourfayaz, P.; Feidt, M. Process development and thermodynamic analysis of a novel power generation plant driven by geothermal energy with liquefied natural gas as its heat sink. Appl. Therm. Eng. 2018, 133, 645-658. [CrossRef]

28. Atienza-Márquez, A.; Bruno, J.C.; Akisawa, A.; Nakayama, M.; Coronas, A. Fluids selection and performance analysis of a polygeneration plant with exergy recovery from LNG regasification. Energy 2019, 176, 1020-1036. 
29. Quoilin, S.; Van Den Broek, M.; Declaye, S.; Dewallef, P.; Lemort, V. Technoeconomic survey of Organic Rankine Cycle (ORC) systems. Renew. Sustain. Energy Rev. 2012, 22, 168-186. [CrossRef]

30. Zhang, X.; Zhang, C.; He, M.; Wang, J. Selection and Evaluation of Dry and Isentropic Organic Working Fluids Used in Organic Rankine Cycle Based on the Turning Point on Their Saturated Vapor Curves. J. Therm. Sci. 2019, 28. [CrossRef]

31. Shi, W.; Pan, L. Optimization Study on Fluids for the Gravity-Driven Organic Power Cycle. Energies 2019, 12, 732. [CrossRef]

2019 by the authors. Licensee MDPI, Basel, Switzerland. This article is an open access article distributed under the terms and conditions of the Creative Commons Attribution (CC BY) license (http://creativecommons.org/licenses/by/4.0/). 